\title{
Exploring the Talent Training Mode of Automobile Service Engineers with the Characteristics of Excellent Teacher Training
}

\author{
Xiaojuan Xing \\ School of Mechanical and Electrical Engineering and Automotive Services, Wuhan Business \\ University, Wuhan, Hubei, 430056, China
}

Keywords: Excellent engineer; training mode

\begin{abstract}
The cultivation of "excellent engineers" in automobiles is of great significance to the establishment of an innovative country in China. The paper outlines the current situation of the cultivation of undergraduate students in mechanical engineering in China. In view of the problems exposed in the process of training mechanical professionals, starting from the three aspects of teacher team building, curriculum system and teaching method reform, the company will improve the quality of automobile talents, to promote China's transition from a manufacturing power to an innovative power.
\end{abstract}

\section{Introduction}

In the 21st century, the development of science and technology is changing with each passing day. The competition between countries is ultimately the competition of science and technology and talents. As the foundation of other industries, manufacturing has become an important criterion for measuring a country's overall national strength. China is a big manufacturing country. The colleges and universities send a large number of engineering and technical talents to the manufacturing industry every year. Mechanical professionals are an important part of it. In order to better enhance the employment competitiveness of graduates and also cultivate talents for innovative countries, the Ministry of Education and various ministries and commissions launched the "Engineering Excellence Program” in 2010. The plan plays an important role in demonstrating and guiding the development of talents for higher education in the face of social needs and comprehensively improving the quality of engineering education personnel training. The integrity and innovation of the traditional education model provides an important way for the cultivation of "excellent engineers” in the automotive industry[1].

\section{Problems in the training of automotive undergraduate students}

A series of problems arising in the cultivation of automotive undergraduate students are related to the undergraduates' own ability and quality; on the other hand, they are also the most important aspect, which is related to China's current education system. First, from the expansion of the enrollment in the late 1990s to the end of the 2012 undergraduate expansion, the number of undergraduate enrollments has increased year by year. Although the government's investment in 
schools has increased, it has not kept pace with the expansion of schools, classroom laboratories, etc. The teaching resources are seriously insufficient, and the per capita possession of teaching resources is decreasing. Some schools have to compress and simplify the original curriculum, which leads to the lack of solid foundation knowledge and professional knowledge after graduation, which seriously affects the quality of personnel training, and also affects the society's confidence in mechanical engineering graduates. Secondly, influenced by traditional elite education, the training mode of automobile undergraduate majors in China is still mainly based on teacher's classroom theory teaching, combining experimental teaching and production internship. However, due to various reasons, students' experimental and production internships are weakened, and students have Most of them are on the paper, and their practical ability is seriously insufficient, which is out of line with the needs of enterprises. Thirdly, most of the teachers who taught engineering in universities in China in the last century have had experience in corporate work, and some of them even have experience in working in famous foreign companies or laboratories[2]. The theoretical and practical levels are very high. With the expansion of higher education, there have been fewer students and fewer teachers. The newly recruited college teachers are mostly graduated doctors. They are generally devoted to pure theoretical research and lack of engineering practice experience. In the process of teaching students, it is often based on the textbook, and it is impossible to give students a deeper expansion in the knowledge level.The following is the distribution of influence weights in teaching.

Table 1 Distribution of influence weights in teaching

\begin{tabular}{|c|c|c|c|}
\hline Index & Equipment & Teacher & Money \\
\hline Weight & 0.4365 & 0.2124 & 0.3511 \\
\hline
\end{tabular}

\section{Keeping up and innovating the construction of the teaching staff}

Teachers are evangelists who are in direct contact with students. The strength of teachers' teaching ability directly affects the level of undergraduates. Therefore, strengthening the construction of the teaching staff of colleges and universities has a crucial role in the quality of undergraduate education. Young teachers are the main force in the faculty of colleges and universities. They usually have high academic level and new knowledge structure, and are easy to communicate with students. They are creative, but they lack teaching theory and engineering practice experience. In view of the characteristics of young teachers, it is necessary to strengthen the pre-job training of young teachers, adhere to the teaching assistants, trials and other systems, so that young teachers gradually enter the role of teachers. Regularly organize various exchanges of teaching experience, teaching quality assessment and consulting services, vigorously implement the "Blue Project" and the Young Teacher Mentoring System, and build a platform for young teachers to demonstrate their teaching ability and career development, and promote the healthy growth of young teachers. At the same time, we will actively carry out special trainings such as teacher teaching theory, teaching skills, teaching reform, teaching research, etc., to meet the needs of teachers' individualized, professional development and talent cultivation characteristics, and improve the teaching ability of young teachers. In terms of the cultivation of teachers' practical experience, relying on relevant institutions of higher learning and large and medium-sized enterprises, we will promote corporate training for professional teachers, especially young teachers, and improve the regular practice of teachers to enterprises[3]. In addition, study and formulate the basic norms and related systems for enterprise teaching operation management, and establish and improve the system for selecting and hiring enterprise teachers. Select some senior technicians and senior engineers to serve as teachers, and comprehensively improve the theoretical and practical 
level of the teaching staff.

\section{The discipline and innovation of the curriculum system}

\subsection{Reform of professional basic courses}

China's automotive professional basic courses include mechanical principles, mechanical design, engineering mechanics, etc. Most of these courses are systematic, and the content is repeated and relatively backward. In the process of basic curriculum reform, we must deal with the choice of traditional curriculum content, and select and compress the content of traditional curriculum to highlight the inheritance and development of the essence of traditional content. At the same time, it is necessary to take the economic and social development needs as the guide, aim at the frontier of discipline development, and incorporate some advanced technologies and methods at home and abroad in the course content, reflecting the advancement of the basic curriculum reform. Drawing on the achievements of the "Eleventh Five-Year" curriculum construction and reform, make full use of modern information technology, improve the requirements of curriculum construction, and improve the level of curriculum construction. On the basis of updating and perfecting the teaching content, we should optimize the curriculum and form a professional core curriculum group with distinctive characteristics[4]. For example, in the direction of mechanical design and manufacturing, based on the three-dimensional parametric design course, the professional basic courses and plastic mold design, CNC machining technology, mechanical manufacturing equipment and design and other professional courses and curriculum design, internship, training links are built on the specific The organic combination of courses, the purpose of refining the curriculum and optimizing the curriculum system is conducive to cultivating students' sense of innovation and innovation.The course teaching mode is as follows.

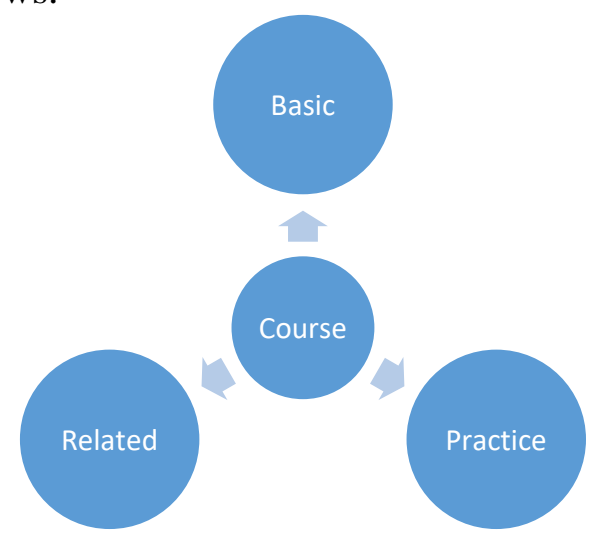

Figure 1 Course teaching mode

\subsection{Combine professional qualification examinations and offer related courses}

As a strong affirmation of the ability of certificate holders, professional qualification certificates are gaining more and more attention in modern society. However, the courses offered by colleges and universities focus on the professors of basic theories, which are far from the relevant content of the vocational qualification examinations. In order to pass the vocational qualification examination, students have to participate in some training institutions in the society to conduct vocational qualification training, which undoubtedly increased their energy and money. The school can refer to the content of the vocational qualification examination in the course arrangement, and provide relevant courses under the condition of ensuring the strength of teachers and the quality of teaching, and integrate the professional qualification certification into normal teaching, so as to reduce the 
burden of students and improve the professional quality of students[5]. For example, in combination with the engineering training session, according to the students' self-selection, provide the examination and examination training for the fitters, electricians, machine tool operators and other types of work, and form a system to complete the training from intermediate workers, senior workers to technicians within the four-year system.

\subsection{Establish an effective practical teaching curriculum system}

Practical teaching is a key link in the training system of engineering talents. First, systematically and holistically design the curriculum under the framework of practical education, establish a practical education platform, and guarantee it in the talent training program. Secondly, integrate the resources of the whole school and establish a practical education system that integrates professional practice teaching, experimental teaching, engineering training, social practice, entrepreneurship training and employment guidance. Forming a combination of practice and education, so that all aspects of the school can be unified, around talent training, scientific planning and effective implementation of practical education, and further improve the quality of personnel training.

\section{Conclusion}

The "Engineering Excellence Program" is intended to train a group of engineering and technical personnel who are oriented to the world, face the future, have strong innovation ability and adapt to economic and social development, and provide an intellectual foundation for China to build an innovative country and realize industrialization and modernization. Taking the faculty, curriculum system and teaching methods as the starting point, keeping the innovation and actively exploring the scientific engineering, practical ability and humanistic literacy integration of the automobile "excellent engineer" training mode, can cultivate more high quality and specialization. The high-level mechanical talents play a greater role in promoting the transformation of China from a manufacturing power to a manufacturing power.

\section{References}

[1] Broadhurst, Sarah. Pioneering female automotive engineer [J]. Professional Engineering, 2015, 28(8).

[2] Colias, Mike. GM sees Bolt as proof of its forward thinking [J]. Automotive News, 2016, 90(6707).

[3] Parameshwaran, R,Srinivasan, P S S,Punniyamoorthy, M. Modified closed loop model for service performance management[J]. The International Journal of Quality \&amp; Reliability Management, 2009, 26(8).

[4] Colias, Mike. GM engineers take retail road trips [J]. Automotive News, 2013, 87(6572).

[5] Truett, Richard. William Clay Ford's luxury-car legacy [J]. Automotive News, 2014, 88(6612). 